\title{
Upregulation of Nerve Growth Factor in Central Amygdala Increases Sensitivity to Opioid Reward
}

\author{
Bihua Bie', Yan Wang', You-Qing Cai', Zhi Zhang', Yuan-Yuan Hou' and Zhizhong Z Pan*,' \\ 'Department of Anesthesiology and Pain Medicine, The University of Texas MD Anderson Cancer Center, Houston, TX, USA
}

\begin{abstract}
The rewarding properties of opioids are essential driving force for compulsive drug-seeking and drug-taking behaviors in the development of opioid-mediated drug addiction. Prior drug use enhances sensitivity to the rewarding effects of subsequently used drugs, increasing vulnerability to relapse. The molecular mechanisms underlying this reward sensitization are still unclear. We report here that morphine that induced reward sensitization, as demonstrated by reinstatement of the behavior of conditioned place preference (CPP) with sub-threshold priming morphine, epigenetically upregulated the output activity of Ngf encoding the nerve growth factor (NGF) by increasing histone $\mathrm{H} 4$ acetylation in the rat central nucleus of the amygdala (CeA). NGF locally infused into the CeA mimicked the morphine effect in inducing new functional delta-opioid receptor (DOR) that was required for the reward sensitization, and morphineinduced reward sensitization was inhibited by blocking NGF receptor signaling in the CeA. Histone deacetylase inhibitors that increased the acetylation level at the Ngf promoter and NGF expression in the CeA also induced reward sensitization in a CeA NGF signaling- and DOR-dependent manner. Furthermore, CeA-applied NGF substituted prior morphine to induce reward sensitization in naive rats and also substituted priming morphine to reinstate the CPP induced by prior morphine. Thus, epigenetic upregulation of NGF activity in the CeA may promote the behavior of opioid reward and increase the sensitivity to the rewarding effect of subsequent opioids, a potentially important mechanism in drug addiction. Neuropsychopharmacology (2012) 37, 2780-2788; doi:10.1038/npp.2012.144; published online 8 August 2012
\end{abstract}

Keywords: nerve growth factor; delta-opioid receptor; epigenetic modulation; opioid reward; drug sensitization; addiction

\section{INTRODUCTION}

Drug addiction is a chronically relapsing neuropsychiatric disorder characterized by compulsive drug taking, which is driven by the rewarding effect of drugs of abuse, including opioids, and by a negative emotional state of withdrawal syndrome (Hyman et al, 2006; Koob, 2008). Prior use of abused drugs can augment the sensitivity to the effects of subsequently administered drugs, a likely cause for relapse (Koob et al, 2009), but the underlying neurobiological mechanisms remain largely unclear. Among drug rewardrelated brain areas, the central nucleus of the amygdala $(\mathrm{CeA})$ has emerged recently as an important brain region that mediates stimulus-reward learning and drug-seeking behaviors in drug addiction (Baxter and Murray, 2002; Gottfried et al, 2003; Le Merrer et al, 2009). Abused drugs induce long-lasting, multifaceted neural maladaptations in brain circuits, particularly glutamate synapses, which have a

*Correspondence: Dr ZZ Pan, Department of Anesthesiology and Pain Medicine, Unit 110, The University of Texas-MD Anderson Cancer Center, 1515 Holcombe Boulevard, Houston, TX 77030, USA, Tel: + | 713792 5559, Fax: + | 713745 3040,

E-mail: zzpan@mdanderson.org

Received I4 March 2012; revised 5 July 20 I2; accepted 6 July 2012 central role in learning and adaptive responses to repeatedly administered drugs of abuse (Carlezon and Nestler, 2002; Jones and Bonci, 2005; Luscher and Malenka, 2011; Russo et al, 2010; Siggins et al, 2003).

Opioids effects are mediated by three types of opioid receptors: mu (MOR), delta (DOR), and kappa (Le Merrer et al, 2009; Pan, 1998; Waldhoer et al, 2004). The rewarding effect of opioids is primarily mediated by MOR (Contet et al, 2004; Matthes et al, 1996), but the role of DOR in opioid reward and drug addiction is still largely unknown (Le Merrer et al, 2009). Recent studies show that DOR in central neurons normally lacks function because of its constitutively intracellular localization, but becomes functional through membrane trafficking under various pathological conditions including chronic opioid exposure (Bie et al, 2009b, 2010; Cahill et al, 2007; Commons, 2003; Hack et al, 2005; Ma et al, 2006). This indicates that DOR may have a critical role in adaptive responses and neuronal plasticity underlying the mechanisms for chronic opioid-associated diseases such as drug addiction and drug sensitization in relapse.

The neurotrophin brain-derived neurotrophic factor (BDNF) has been demonstrated to promote the behavior of cocaine addiction (Graham et al, 2007; Lu et al, 2004). In contrast, 
the role of nerve growth factor (NGF) in drug addiction is still unclear. For example, although NGF was epigenetically downregulated in the serum of alcohol-dependent patients after withdrawal (Heberlein et al, 2011), infusion of NGF into the ventral tegmental area failed to change cocaineseeking behavior, which was enhanced by similar infusion of BDNF (Lu et al, 2004). We have shown recently that NGF can induce new functional DOR in CeA neurons, indicating a potential NGF role in CeA-related behavior of opioid addiction (Bie et al, 2010). In this study, we examined opioid regulation of $\mathrm{Ngf}$ gene activity in CeA neurons and roles of CeA NGF in opioid-induced behaviors of reward sensitization.

\section{MATERIALS AND METHODS}

\section{Animals and Microinjection}

All procedures involving the use of animals conformed to the guidelines by the Institutional Animal Care and Use Committee of the University of Texas MD Anderson Cancer Center. Male Wistar rats, weighing 200-250 g, were used. General methods for CeA-specific drug infusion have been described in details in our previous studies (Bie et al, 2009a; Zhu et al, 2007). A 26-gauge single guide cannula was implanted, aiming at the CeA (AP: $-2.3 \mathrm{~mm}$; L: $\pm 4.0 \mathrm{~mm}$; $\mathrm{V}:-8.0 \mathrm{~mm}$ ) on both sides of the brain before conditioning treatment. Drugs were infused bilaterally in a volume of $0.5 \mu$ into the $\mathrm{CeA}$ on each side through a 33-gauge single injector with an infusion pump at a rate of $0.1 \mu \mathrm{l} / \mathrm{min}$. The injection sites for the CeA were histologically verified afterward by injecting $0.5 \mu \mathrm{l}$ of a blue dye, as shown before (Bie et al, 2009a). For CeA pre-treatment, Trichostatin A (TsA, $2.5 \mu \mathrm{g}$ ) was infused into the CeA $4 \mathrm{~h}$ before conditioning with priming morphine. K252a (24 ng) was infused into the CeA $30 \mathrm{~min}$ before the posttest or conditioning with priming morphine, or was co-infused with TsA. Naltrindole (NTD, $0.45 \mu \mathrm{g}$ ) was infused once $30 \mathrm{~min}$ before the conditioned place preference (CPP) test 1 day after CPP establishment or 30 min before the CPP test for CPP reinstatement with priming morphine. DMSO was used as vehicle for these drugs. For NGF substitution of morphine conditioning, NGF $(0.05 \mu \mathrm{g})$ was infused into the CeA $4 \mathrm{~h}$ before priming morphine. For NGF-reinstated CPP, the rat was conditioned (confined to the previous morphine-paired chamber) three times at $15 \mathrm{~min}, 2 \mathrm{~h}$, and $4 \mathrm{~h}$ after a single bilateral CeA infusion of NGF at the same dose, followed by saline conditioning on the following day. NGF-reinstated CPP was examined on the 3 days (D1-D3) following the day of saline conditioning.

\section{Conditioned Place Preference}

General methods of CPP have been described in our previous reports (Bie et al, 2009b; Zhu et al, 2007). With a standard three-chamber rat CPP apparatus (MED Associates, St Albans, VT), the conditioning procedure consisted of four phases. Phase 1 (habituation, days 1-2): after an intraperitoneal (i.p.) saline injection, a rat was allowed to move freely between the chambers for $30 \mathrm{~min}$ each day. Phase 2 (pretest, day 3): after an i.p. saline injection, a CPP test (pretest) was conducted in a 30-min test period, which determines the baseline chamber preference or chamber bias. Phase 3 (morphine conditioning, days 4-11): the rat in the morphine group was injected with morphine $(10 \mathrm{mg} / \mathrm{kg}$, i.p.) or saline and was immediately confined in a chamber for $20 \mathrm{~min}$ on alternate days (four morphine and four saline sessions). Conditioning with morphine was paired with the non-preferred chamber of two conditioning apparatuses with different amount of equipment bias to access equipment bias-independent CPP measurements. CPP also can be consistently induced by morphine paired with the preferred chamber (Zhu et al, 2007). Rats in the saline group were similarly conditioned with saline only (eight saline sessions). Phase 4 (posttest, day 12): after an i.p. saline injection, a CPP test (posttest) was performed for $30 \mathrm{~min}$ on the conditioned rat and CPP behavior was determined by comparing the pretest and posttest on the same rat. The preference data were expressed as the percentage of time in the morphinepaired chamber over the total time in both test chambers.

\section{CPP Extinction and Reinstatement}

For CPP extinction, rats were injected with saline and then confined to the previous morphine-paired chamber for 20 min daily for 10 days. CPP extinction was confirmed by a CPP test. To reinstate the CPP, the rat was injected with morphine $(1 \mathrm{mg} / \mathrm{kg}$, i.p.) and then confined to the previous morphine-paired chamber for $20 \mathrm{~min}$, and on the following day, the rat was injected with saline and confined in the other chamber for $20 \mathrm{~min}$. A day later, a CPP test was performed to confirm the CPP reinstatement. The effect of a CeA-infused drug was examined by a CPP test 1 day after posttest or after CPP reinstatement. For NGF-reinstated CPP, bilateral CeA infusion of NGF $(0.05 \mu \mathrm{g} / 0.5 \mu \mathrm{l}$ each side) substituted priming morphine for conditioning at $15 \mathrm{~min}, 2 \mathrm{~h}$, and $4 \mathrm{~h}$ after NGF infusion, followed by CPP tests over 3 days.

\section{Chromatin Immunoprecipitation Assay (ChIP)}

The ChIP assay was performed as we previously described (Wang et al, 2007; Zhang et al, 2011). CeA tissues were collected from rats at different behavioral stages of CPP immediately after the posttest for the stage of CPP establishment, after extinction training and confirming CPP test for extinction, and after test of reinstated CPP for reinstatement. Tissues were cross-linked with $2 \%$ formaldehyde. Chromatin was solubilized and sonicated to produce fragments of approximately $400 \mathrm{bp}$. One-third of the pre-immunoprecipitation (IP) lysate was used to determine the input of DNA. The input-level control was processed with the eluted IP. The polyclonal antibody against acetylated $\mathrm{H} 4$ at K5, K8, K12, and K16 (Upstate Biotechnology) was used at 1:100 dilution. Immunocomplexes were recovered by adding $30 \mu \mathrm{l}$ of the salmon sperm DNA/protein A agarose beads. After reversal of the cross-linking between histones and DNA, DNA fragments were purified and chromatin from crosslinked CeA tissues was sonicated and IP with the antiacetylated $\mathrm{H} 4$ antibody. DNA co-IP with acetylated histone $\mathrm{H} 4$ and input DNA were purified by reverse cross-linking, followed by phenol-chloroform extraction. DNA was then quantified in a NanoDrop spectrophotometer (NanoDrop Technologies). Global histone $\mathrm{H} 4$ acetylation levels were expressed as the ratio of the amount of DNA associated with 
the acetylated chromatin to input DNA. The entire protocol was repeated four times to obtain the means and SEM.

\section{PCR}

Real-time PCR was performed using the ABI SYBR Green PCR protocol (Applied Biosystems) as described before (Ma et al, 2006). Primers were designed to amplify approximately 200-bp fragments within the $N g f$ transcriptional control region. Gapdh was used as the internal control. For ChIP assay to detect $\mathrm{H} 4$ acetylation across the $\mathrm{Ngf}$ promoter region, the primers sets were: Ngf ( $5^{\prime}$-TTTTTCGGAGCTG GGGACTGA-3', $5^{\prime}$-AAGGAGATATAGGGGGAGGTTGTA-3') and Gapdh (5'-GAATGGATTTGGCCGTATTG-3', 5'-GATCT CGCTCCTGGAAGATG-3'). Amplifications were run in triplicate and the changes on histone $\mathrm{H} 4$ acetylation were calculated by the $\Delta \Delta \mathrm{CT}$ method. The amount of DNA recovered in the IP was expressed as the ratio of input DNA with the equation: IP/input $=2 \wedge\left(\mathrm{CT}^{\mathrm{Input}}-\mathrm{Ct}^{\mathrm{IP}}\right)$. Reverse transcription and real-time PCRs were performed in triplicate with $\mathrm{Ngf}$ exon primers ( $5^{\prime}$-AAGTCAGCAGGGGATGA CAC- $3^{\prime}, 5^{\prime}$-CACATCTGCAGGGGATTTCT- $\left.3^{\prime}\right)$, and $\beta$-actin primers ( $5^{\prime}$-GTCGTACCACTGGCATTGTG-3' ${ }^{\prime} 5^{\prime}$-CTCTCAG CTGTGGTGGTGAA-3').

\section{Synaptosome Preparations and Western Blot}

Detailed methods of western assays and synaptosome preparations have been reported previously (Bie et al, 2010). CeA tissues were gently homogenized in ice-cold $0.32 \mathrm{M}$ sucrose buffer and centrifuged at $1000 \times g\left(4{ }^{\circ} \mathrm{C}\right)$. The supernatant was collected and centrifuged at $10000 \times g$ $\left(4{ }^{\circ} \mathrm{C}\right)$, and the synaptosomal pellet was re-suspended in a lysis buffer $(0.1 \%$ Triton X-100, $150 \mathrm{mM} \mathrm{NaCl}, 25 \mathrm{mM} \mathrm{KCl}$, $10 \mathrm{mM}$ Tris- $\mathrm{HCl}, \mathrm{pH}$ 7.4, with protease inhibitors). For total protein preparations, CeA tissues from saline- and morphine-conditioned rats were homogenized in the lysis buffer, the lysates were centrifuged at 14000 r.p.m., and the supernatant was used for SDS-PAGE. Protein concentrations were determined by the Bio-Rad (Hercules, CA) protein assay kit. Proteins were separated and electrotransferred onto nitrocellulose membrane. The amount of protein loaded in each lane was $20 \mu \mathrm{g}$. Samples were incubated overnight at $4{ }^{\circ} \mathrm{C}$ with a primary antibody for NGF (1:1000, Sigma), DOR $(1: 250$, Santa Cruz Biotechnology), $\beta$-actin $(1: 200$, Santa Cruz Biotechnology), or synaptophysin $(1: 2500$, Millipore). For immunobloting, $15 \%$ SDS-polyacrylamide gel was used for NGF and $10 \%$ gel for DOR with composition including 29:1 40\% acrylamide, sodium dodecyl sulfate, $\mathrm{H}_{2} \mathrm{O}, N, N, N^{\prime}, N^{\prime}$-tetramethylethylenediamine, and ammonium persulfate. After washes, the blots were incubated with horseradish peroxidase-conjugated secondary antibody $(1: 10000)$ (Amersham, Arlington Heights, IL) for $1 \mathrm{~h}$. Immunoreactive proteins were detected by the enhanced chemiluminescence advance kit (Amersham). The intensity of bands was digitally captured and quantitatively analyzed with the software Kodak 1D (Eastman, Kodak, Rochester, NY). The immunoreactivity of target proteins was normalized to that of $\beta$-actin for total protein, or to the specific synaptic terminal marker synaptophysin for synaptosomal proteins.

\section{Slice Preparations and Whole-Cell Recording}

General recording methods are the same as in previous studies (Bie et al, 2009b, 2010). Visualized whole-cell voltage-clamp recordings were obtained from neurons in the medial part of the CeA in a slice with a glass pipette (resistance 2-4 M 2 ) containing (in $\mathrm{mM}$ ): K-gluconate, 126; $\mathrm{NaCl}, 10 ; \mathrm{MgCl}_{2}$, 1; EGTA, 11; HEPES, 10; ATP, 2; GTP, 0.25; $\mathrm{pH}$ adjusted to 7.3 with $\mathrm{KOH}$; osmolarity $280-290 \mathrm{mOsm} / \mathrm{l}$. Electrical stimuli of constant current $(0.25 \mathrm{~ms}, 0.04-0.2 \mathrm{~mA})$ were used to evoke glutamate-mediated excitatory postsynaptic currents (EPSCs) in $\mathrm{GABA}_{\mathrm{A}}$ receptor antagonist bicuculline $(30 \mu \mathrm{M})$. Recordings in slices from all rats were made in a morphine-free solution 1-3 h after making the slice preparation. Drugs were applied through the bath solution.

\section{Statistics and Materials}

Numerical data of EPSCs and protein expression were statistically analyzed with paired or unpaired Student's tests. Behavioral data were statistically analyzed with one-way or two-way ANOVA with repeated measures and the Bonferroni's post hoc test. Data were presented as means \pm SEM and $p<0.05$ was deemed statistically significant. Morphine sulfate and [D-Pen $\left.{ }^{2}, \mathrm{D}-\mathrm{Pen}^{5}\right]$-enkephalin (DPDPE) were supplied by the Drug Program of the National Institute on Drug Abuse. Other drugs were purchased from SigmaAldrich or Tocris Bioscience (Ellisville, MO).

\section{RESULTS}

As we reported before (Bie et al, 2009b; Zhu et al, 2007), conditioning with morphine (10 $\mathrm{mg} / \mathrm{kg}$, i.p.), but not saline, in rats consistently induced the CPP behavior (Figure 1a), a common behavioral measure of drug reward in rodents (Tzschentke, 2007). The established CPP behavior was extinguished after daily conditioning with saline only for 10 days ( $n=15$ rats) and the CPP was reinstated by conditioning with a single, sub-threshold dose of priming morphine ( $1 \mathrm{mg} / \mathrm{kg}$, i.p., $n=10)$, which was ineffective in salineconditioned naive rats $(n=7$, Figure $1 \mathrm{~b})$. This suggests that pre-exposure to morphine increases the sensitivity to the rewarding effect of subsequent morphine.

Given our recent finding of opioid-induced increase in NGF activity in brainstem pain-modulating neurons (Bie et al, 2010), we determined molecular mechanisms underlying the morphine-induced sensitivity increase, focusing on epigenetic regulation of CeA NGF expression and its functions. We found that the global level of histone acetylation was significantly increased in CeA lysates from rats with established CPP (Figure 1c). After CPP extinction, the global histone acetylation returned to pre-CPP levels, and increased again following CPP reinstatement. Using the CHIP assay (Zhang et al, 2011), we found that the level of histone $\mathrm{H} 4$ acetylation across the $N g f$ promoter region displayed similar CPP-correlated changes to those of global acetylation levels, increasing on CPP establishment and reinstatement (Figure 1d). The priming morphine failed to change the level of either global acetylation or acetylation in the $N g f$ promoter region in saline-conditioned control rats. The acetylation level of histone $\mathrm{H} 4$ at the Gapdh promoter 
a
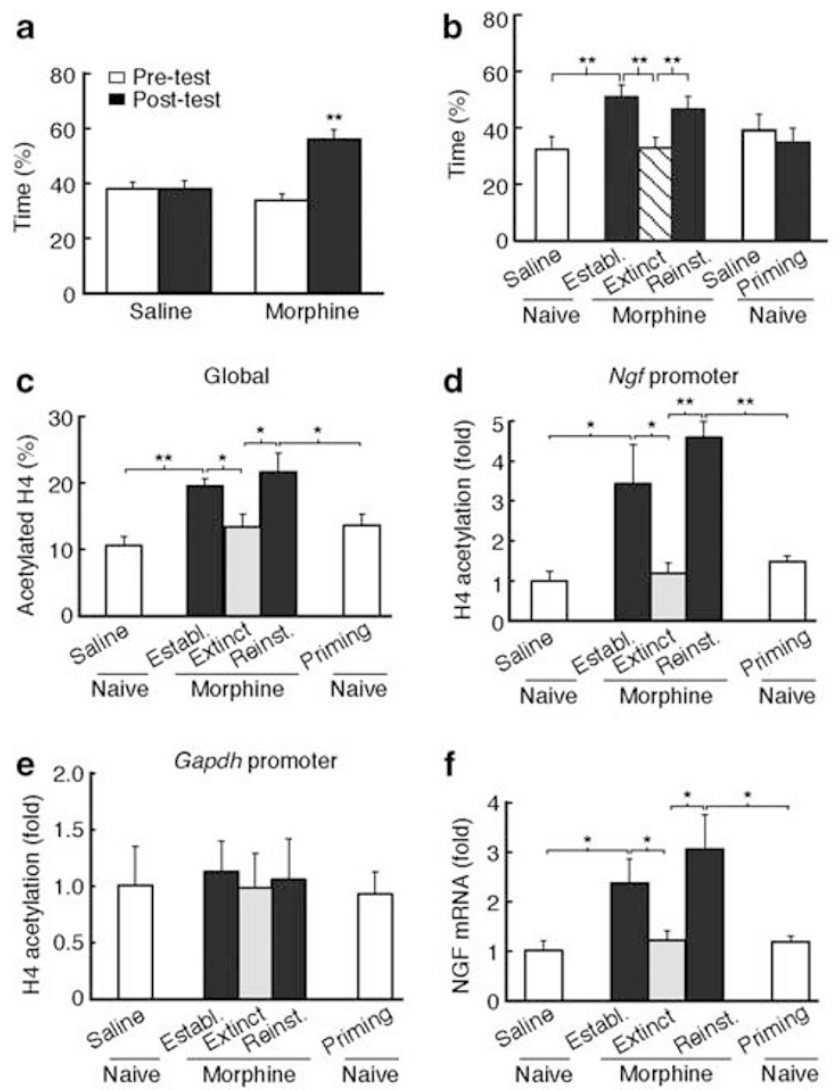

\section{f}

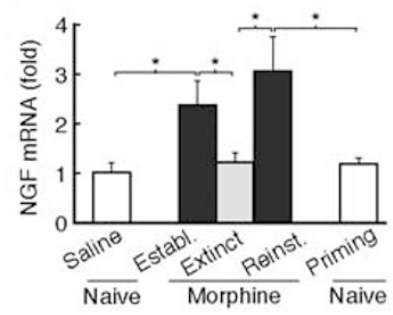

g
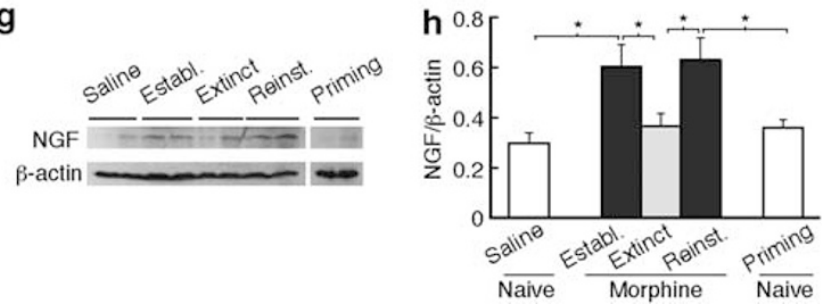

Figure I Morphine epigenetically activates the $\mathrm{Ngf}$ gene and the expression of nerve growth factor (NGF) in the central nucleus of the amygdala (CeA) of rats with increased sensitivity to morphine reward. (a) Behaviors of conditioned place preference (CPP), expressed as the time spent in the conditioning chamber before (pretest) and after conditioning (posttest), in saline-conditioned rats (one-way ANOVA (same below): $\left.F_{(1,12)}=0.009, n=13\right)$ and in morphine-conditioned rats $\left(F_{(1,25)}=58.47\right.$, $n=26$ ). (b) CPP behaviors in morphine-conditioned rats after CPP establishment $\left(F_{(1,9)}=26.59\right)$, extinction $\left(F_{(1,9)}=52.98\right)$, and reinstatement $\left(F_{(1.9)}=42.06\right)$ by a single priming dose of morphine $(1 \mathrm{mg} / \mathrm{kg}$, i.p.), and in saline-conditioned naive rats either as control or after conditioning with the priming morphine $\left(\mathrm{F}_{(1,6)}=1.08\right) . N=7-15$ rats in each group. (c) Normalized levels of global acetylated histone $\mathrm{H} 4$, expressed as the ratio of DNA associated with the acetylated $\mathrm{H} 4$ to input DNA, in $\mathrm{CeA}$ tissues from saline-conditioned naive rats, from morphine-conditioned rats with CPP established, extinguished and reinstated, and from saline-conditioned naive rats after conditioning with priming morphine. (d, e) Levels of $\mathrm{H} 4$ acetylation across the Ngf promoter region (d) and across the Gapdh promoter region (e) in similar groups of rats to those in (a). N=5-7 rats for each group. (f) Changes in NGF mRNA levels in CeA tissues from similar groups of morphine-conditioned rats at the three indicated CPP stages and of saline-conditioned rats without or after conditioning with priming morphine. $N=5$ rats for each group. $(g, h)$ Representative western blots $(\mathrm{g})$ and group data of NGF protein levels normalized to $\beta$-actin (h) in $\mathrm{CeA}$ tissues from similar rat groups as indicated. $N=5$ rats for each group. Summarized data are mean \pm SEM. ${ }^{*} p<0.05$, $* * * 0.01$. Establ., establishment; Reinst., reinstatement. region was not significantly altered regardless of opioid treatments or CPP conditions (Figure 1e). Thus, it appears that morphine-induced CPP is associated with epigenetic activation of $\mathrm{Ngf}$ transcription through histone hyperacetylation. As expected, we found that both the NGF mRNA and NGF protein levels were also significantly increased in CeA tissues from rats with $\mathrm{CPP}$ establishment and CPP reinstatement, but not after CPP extinction (Figures 1f-h). Additionally, CeA neurons displayed increased expression of NGF detected immunocytochemically in rats with morphine-induced CPP behavior (Supplementary Figure S1).

In CeA slices, the selective DOR agonist DPDPE $(1 \mu \mathrm{M})$, having no effect in CeA neurons from saline-conditioned rats, significantly inhibited the amplitude of evoked glutamatergic EPSCs in 13 of 19 (68\%) cells generally surveyed in $\mathrm{CeA}$ neurons from morphine-conditioned rats displaying established CPP. This appearance of functional DOR was temporally correlated to CPP, present only with CPP established or reinstated by priming morphine (Figures 2a and $b$ ). The priming morphine itself was unable to induce functional DOR in naive rats. To determine a causal role of the DOR in CPP behavior, we then conducted behavioral experiments in rats with an implanted CeA cannula. Bilateral infusion of the selective DOR antagonist NTD $(0.45 \mu \mathrm{g}$ in $0.5 \mu \mathrm{l}$ each side) into the CeA, which blocks DOR function in vivo (Bie et al, 2009a; Cornish et al, 2005; Schmidt et al, 2002; Ward and Roberts, 2007), had no effect on baseline preference behavior in saline-conditioned naive rats, indicating the absence of functional DOR or lack of tonic DOR effect under control conditions. However, in morphine-conditioned rats, NTD significantly inhibited the CPP 1 day after CPP establishment (Figure 2c) when the CPP persisted otherwise (Bie et al, 2009a; Zhu et al, 2007). CeA-applied NTD also significantly attenuated priming morphine-reinstated CPP (Figure 2d).

As morphine epigenetically upregulated $\mathrm{Ng} f$ expression and induced new DOR in CeA neurons, we next determined whether the NGF upregulation and NGF signaling was involved in morphine induction of DOR and reward sensitization. In contrast to its ineffectiveness in control slices, the DOR agonist DEDPE $(1 \mu \mathrm{M})$ significantly inhibited EPSCs in CeA neurons in naive slices incubated with NGF $(100 \mathrm{ng} / \mathrm{ml})$ in vitro for $4 \mathrm{~h}(n=9$ out of $12(75 \%)$ cells surveyed, Figure 3a). The NGF treatment also induced functional DOR ( $n=6$ out of $8(75 \%)$ cells surveyed) in CeA slices from morphine-treated rats with the CPP extinction (Figure $3 \mathrm{~b}$ ). In addition, in CeA slices from morphine-treated rats with either established CPP or reinstated CPP, the DOR agonist was no longer effective after incubating the slices for $4 \mathrm{~h}$ in vitro with $\mathrm{K} 252 \mathrm{a}(0.2 \mu \mathrm{M})$, an inhibitor of the NGF receptor tyrosine receptor kinase (Trk) (Figures $3 \mathrm{c}$ and d). Furthermore, bilateral CeA infusion of K252a (24 ng) inhibited morphine-induced CPP ( $n=6$ rats) whereas it did not alter the preference behavior in saline-conditioned rats $(n=4$ rats, Figure 3e). CeA-infused K252a also attenuated priming morphine-reinstated CPP ( $n=6$ rats, Figure $3 \mathrm{f})$.

Next, we determined whether the epigenetic upregulation of CeA NGF was essential for the reward sensitization. We induced histone hyperacetylation with TsA, a commonly used histone deacetylase inhibitor that increases histone acetylation non-selectively (Finnin et al, 1999; Zhang et al, 2011). Mimicking the effect of morphine conditioning 

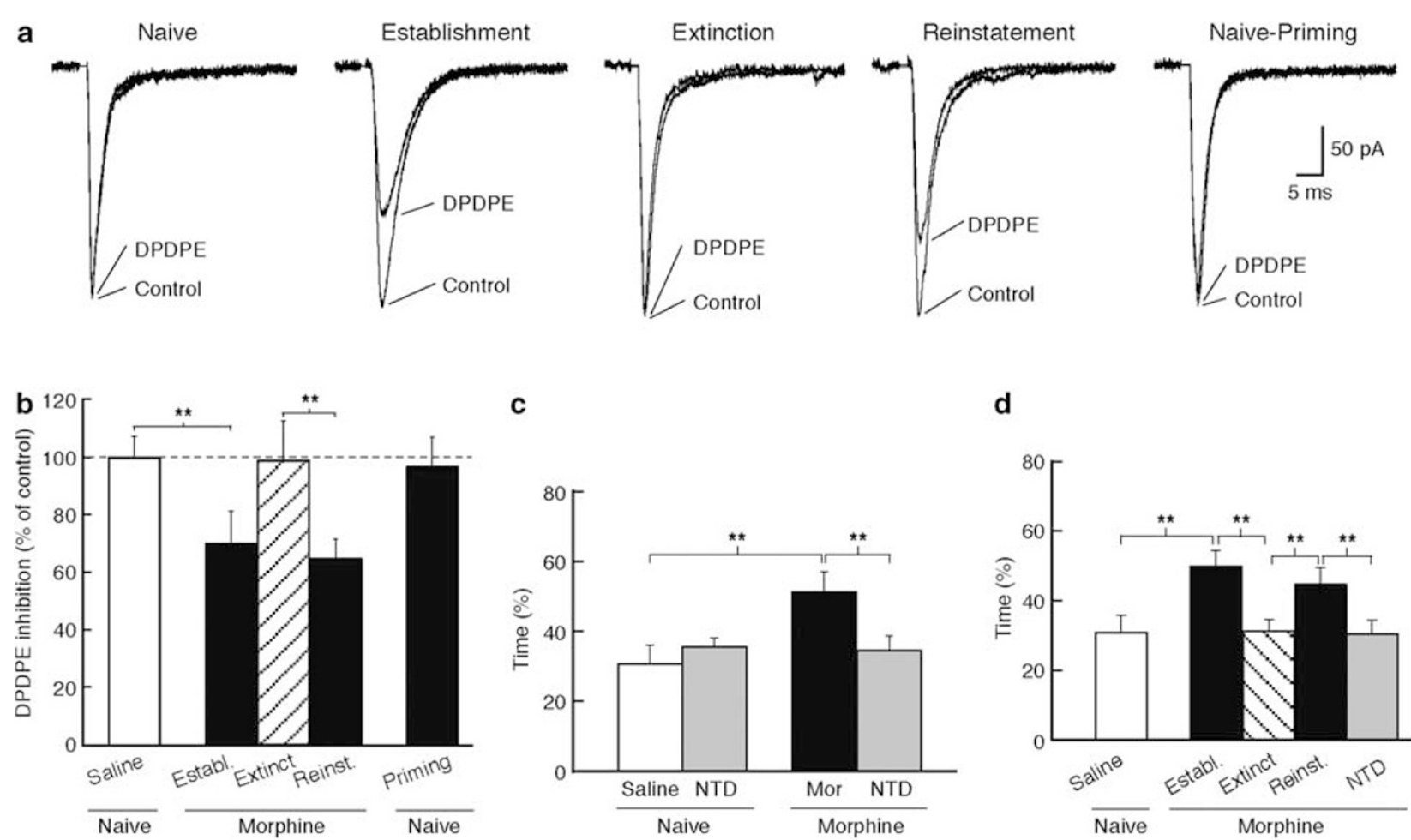

C

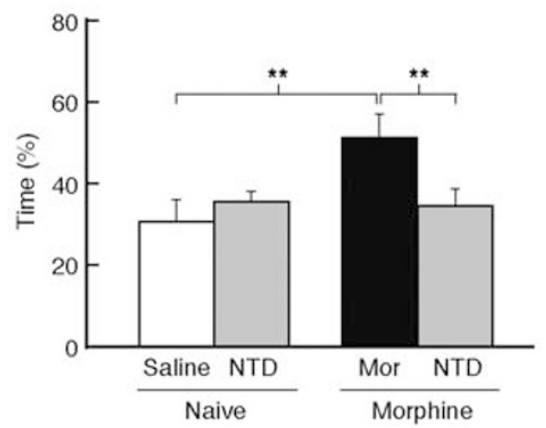

d

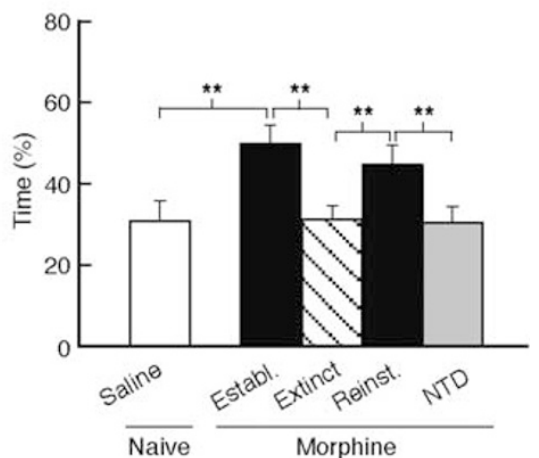

Figure 2 Morphine induces functional DOR that is required for morphine-induced reward sensitization. (a) Representative glutamatergic excitatory postsynaptic currents (EPSCs) in control and in the presence of [D-Pen ${ }^{2}$ D-Pen ${ }^{5}$-enkephalin (DPDPE, I $\mu \mathrm{M}$ ), a selective agonist of the delta-opioid receptor (DOR), in a CeA neuron from a saline-conditioned rat, from morphine-conditioned rats with CPP established, extinguished, and reinstated, and from a saline-conditioned rat after conditioning with priming morphine. (b) Summarized data of the DPDPE effects normalized to controls in the same groups of rats as in (a). $N=9-20$ cells for each group. (c) Effect of the DOR antagonist naltrindole (NTD), infused bilaterally into the CeA ( $0.45 \mu \mathrm{g}$ in $0.5 \mu$ leach side) I day after posttest, on baseline preference in saline-conditioned naive rats $\left(F_{(1,5)}=1.32, n=5\right)$ and in morphine-conditioned rats with $C P P\left(F_{(1,6)}=20.90\right.$, $n=7$ rats). For morphine vs saline comparison, $F_{(1,6)}=18.68$. (d) Effect of NTD, infused similarly into the CeA I day after CPP reinstatement, on the priming morphine-reinstated CPP $\left(F_{(1,8)}=19.28, n=9\right.$ rats). Establishment: $F_{(1,8)}=22.47$, extinction: $F_{(1,8)}=49.62$, and reinstatement: $F_{(1,8)}=33.16$. Summarized data are mean \pm SEM. $* * * 0.01$.

(Figure $1 \mathrm{~b}$ ), pre-treatment of naive rats by CeA infusion of TsA $(2.5 \mu \mathrm{g})$ increased the sensitivity to opioid reward, as priming morphine $(1 \mathrm{mg} / \mathrm{kg})$ induced CPP behavior in TsAtreated, opioid-naive rats $(n=7)$, but not in vehicle-treated rats $(n=5$, Figure $4 \mathrm{a})$. As expected, the CeA pre-treatment with TsA significantly increased the levels of global histone $\mathrm{H} 4$ acetylation, $\mathrm{H} 4$ acetylation on the $\mathrm{Ngf}$ promoter, and NGF mRNA in the CeA from naive rats with priming morphine-induced CPP (Figure 4b). Additionally, expression of CeA NGF protein and synaptosomal DOR protein were also increased in the CeA from these rats (Figures $4 \mathrm{c}-\mathrm{e}$ ). As TsA-induced hyperacetylation is global, we then determined whether the TsA induction of reward sensitization was dependent on NGF signaling in the CeA. We found that, after bilateral $\mathrm{CeA}$ infusion of the Trk receptor antagonist K252a (24 ng), priming morphine could no longer induce CPP in the TsA pre-treated rats (Figure $4 \mathrm{f}$ ), and so was the case after CeA infusion of DOR antagonist NTD $(0.45 \mu \mathrm{g}$, Figure $4 \mathrm{~g})$. In addition, blocking Trk also inhibited the elevated level of CeA synaptosomal DOR protein induced by TsA pre-treatment and priming morphine (Figure 4h).

To further support such a role of CeA NGF in reward sensitization, we determined whether exogenously applied NGF by itself in the CeA was sufficient to induce reward sensitization. In naive rats pre-treated ( $4 \mathrm{~h}$ before) with bilateral CeA infusion of NGF $(0.05 \mu \mathrm{g} / 0.5 \mu \mathrm{l}$ each side), priming morphine $(1 \mathrm{mg} / \mathrm{kg})$ induced significant $\mathrm{CPP}$, which was blocked by CeA infusion of the DOR antagonist NTD (Figure 5a). Priming morphine was not effective on preference behavior in naive rats pre-treated with CeA infusion of saline, nor was the NGF pre-treatment alone in saline-conditioned rats. Therefore, it seems that the acute NGF in the CeA is sufficient to promote the sensitivity to opioid reward in naive rats, substituting prior opioids to induce reward sensitization.

Finally, we determined whether CeA NGF was able to reinstate morphine-induced CPP. After morphine-induced CPP was initially established and then extinct, rats in two separate groups were bilaterally infused with NGF $(0.05 \mu \mathrm{g} /$ $0.5 \mu \mathrm{l}$ each side) or saline into the $\mathrm{CeA}$ and then conditioned in the prior morphine-paired chamber. We found that the CeA NGF-conditioned rats, but not CeA saline-conditioned rats, displayed significant $\mathrm{CPP}$ on the first and second day after the conditioning session (Figure $5 \mathrm{~b}$ ). The infusion site in the CeA is shown in Figure 5c.

\section{DISCUSSION}

We have shown in this study that morphing epigenetically activates the $\mathrm{Ng}$ gene through histone $\mathrm{H} 4$ hyperacetylation 
a

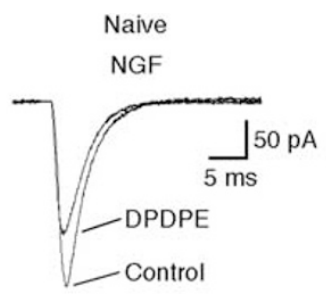

C

Establishment

K252a
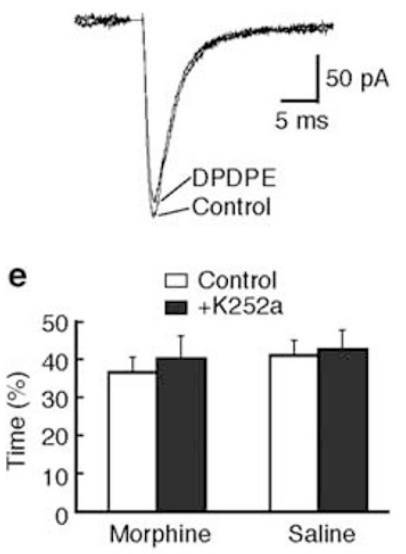

b

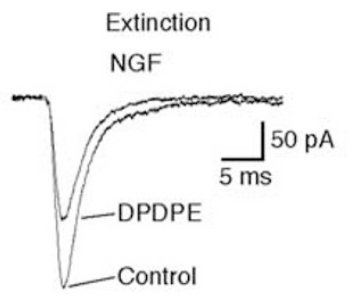

d
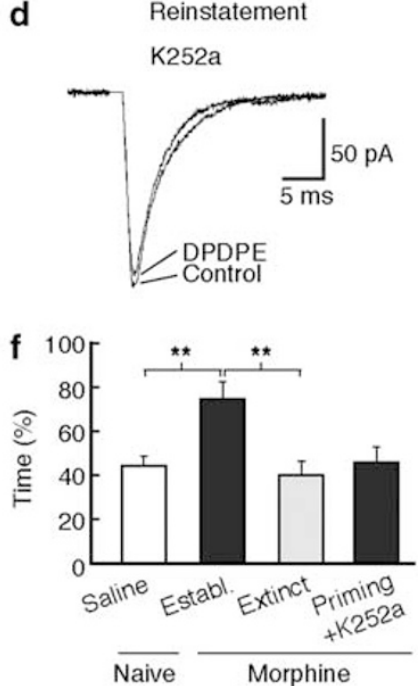
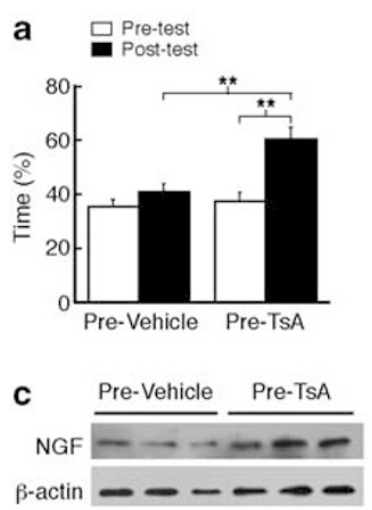

e
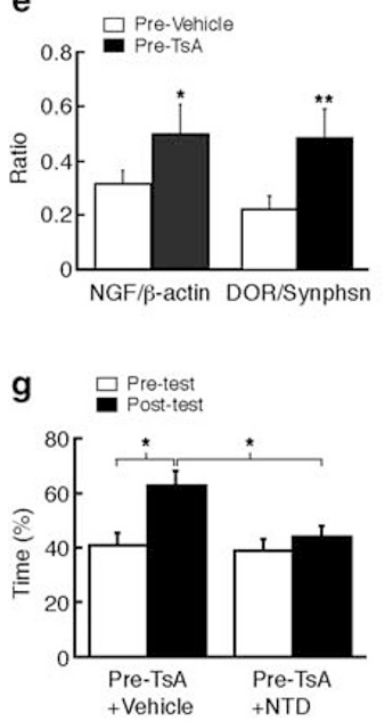
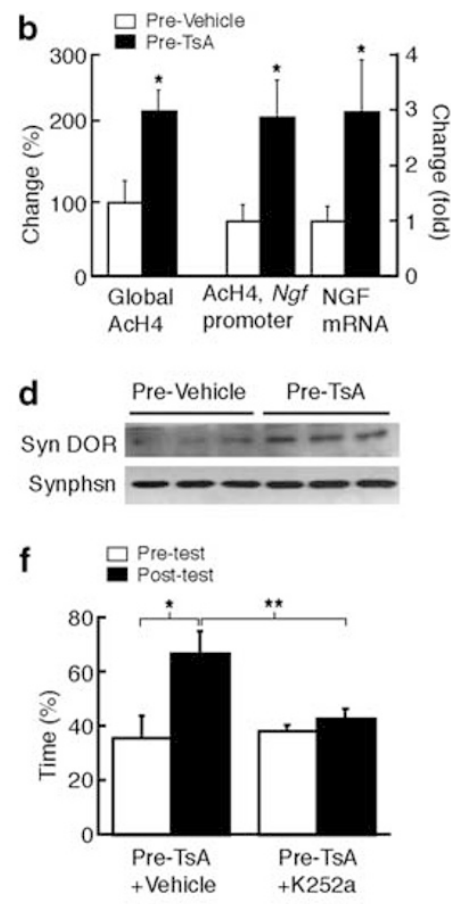

h
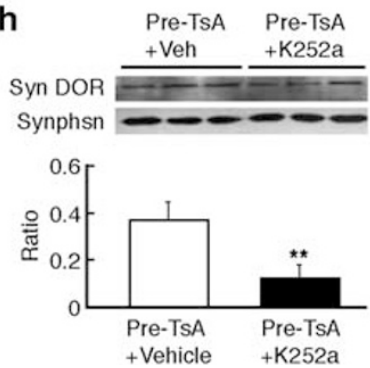

Figure 3 NGF signaling in the CeA is necessary for morphine-induced reward sensitization. (a) Representative effect of DPDPE on EPSCs from a group of CeA neurons (control, $320 \pm 22 \mathrm{pA}$, DPDPE, $224 \pm 17 \mathrm{pA}, n=9$ out of $12(75 \%)$ cells, $p<0.0 \mathrm{I})$ in naive slices treated with NGF $(100 \mathrm{ng} / \mathrm{ml})$ in vitro for $4 \mathrm{~h}$. (b) DPDPE effect on EPSCs (control, $233 \pm 43 \mathrm{pA}$, DPDPE, $148 \pm 29 p A, n=6$ out of $8(75 \%)$ cells, $p<0.01)$ in similar NGF-treated slices from morphine-conditioned rats with CPP extinction. (c, d) DPDPE effects on EPSCs in CeA slices treated in vitro with the tyrosine receptor kinase (Trk) inhibitor K252a (0.2 $\mu \mathrm{M})$ from rats with morphine-established CPP (c, control, $240 \pm 29$ pA, DPDPE, $232 \pm 28$ pA, $n=8, p>0.05$ ) or with priming morphine-reinstated CPP (d, control, $228 \pm 21 \mathrm{pA}$, DPDPE, $214 \pm 21 p A, n=7, p>0.05$ ). (e, f) Effects of pre-treatment with bilateral $\mathrm{CeA}$ infusion of $\mathrm{K} 252 \mathrm{a}(24 \mathrm{ng})$ on preference behaviors in morphine$\left(F_{(1.5)}=0.65\right)$ or saline- $\left(F_{(1.3)}=0.06\right)$ conditioned rats $(e)$ and in saline- or morphine-conditioned rats after CPP extinction $\left(F_{(1,5)}=0.42\right)(f)$. Establishment: $F_{(1,5)}=10.4 \mid$ and extinction: $F_{(1,5)}=|6.7|$. $N=4-6$ rats for each group. Summarized data are mean \pm SEM. $* * * 0.01$.

and increases NGF expression in CeA neurons, resulting in new functional DOR required for the CPP behavior and reward sensitization. In addition, both CeA-applied NGF and pharmacologically increased histone acetylation at the $\mathrm{Ngf}$ promoter appear to be sufficient to mimic the morphine effects in inducing functional DOR and behavior of reward sensitization. Thus, it is likely that $N g f$ in the CeA is one of the target genes activated epigenetically through histone modifications by opioids, and activation of this NGF signaling cascade in CeA neurons may promote behaviors of opioid reward and drug sensitization.

Epigenetic mechanisms for gene regulation involve modifications of chromatin structures in core histone proteins and associated DNA through phosphorylation, acetylation, methylation, and ubiquitination (Dulac, 2010; Jenuwein and Allis, 2001; MacDonald and Roskams, 2009). Particularly, histone acetylation reduces the electrostatic interaction between histone proteins and DNA, thus relaxing chromatin
Figure 4 Histone hyperacetylation induces reward sensitization through CeA NGF signaling. (a) Preference behaviors before (pretest) and after (posttest) conditioning with priming morphine $(1 \mathrm{mg} / \mathrm{kg}$, i.p.) in naive rats pre-treated $4 \mathrm{~h}$ before with bilateral CeA infusion of vehicle $(n=10$ rats) or the histone deacetylase inhibitor Trichostatin A (TsA, $2.5 \mu \mathrm{g}, \mathrm{F}_{(3,40)}=24.82$, $n=12$ rats). (b) Normalized levels of global acetylated histone $\mathrm{H} 4$, acetylated $\mathrm{H} 4$ across the Nof promoter region and NGF mRNA in CeA tissues from priming morphine-conditioned rats pre-treated by $\mathrm{CeA}$ infusion of vehicle or TsA as in (a). N=4-5 rats for each group. (c-e) Western blot lanes (c, d) and summarized data (e) of NGF protein normalized to $\beta$-actin and synaptosomal DOR protein normalized to synaptophysin in CeA tissues from rat groups similar to those in (a). ( $f, g)$ Preference behaviors in priming morphine-conditioned rats pre-treated with CeA infusion of vehicle and TsA plus the Trk antagonist K252a (24 ng, $F_{(3,14)}=24.52$, f), or TsA plus the DOR antagonist NTD $(0.45 \mu \mathrm{g}$, $\left.F_{(3,14)}=5.82, g\right)$. (h) Western blots and summarized data of synaptosomal DOR protein in CeA tissues from the two rat groups as in ( $f$ ). Summarized data are mean \pm SEM. $* p<0.05$, $* * * 0.0$ I. Syn, synaptosomal; Synphsn, synaptophysin; $\vee$ eh, vehicle.

structure and making DNA more accessible to transcriptional regulators for gene activation (Kouzarides, 2007; Kurdistani et al, 2004; Strahl and Allis, 2000). An important leap in addiction research is the recent revelation of cocaine-induced epigenetic modulations of certain gene activities (Robison and Nestler, 2011). Nearly all addiction studies concerning epigenetic mechanisms have focused on the psychomotor stimulant cocaine. The most prominently described target gene of cocaine so far is Bdnf (encoding 
a
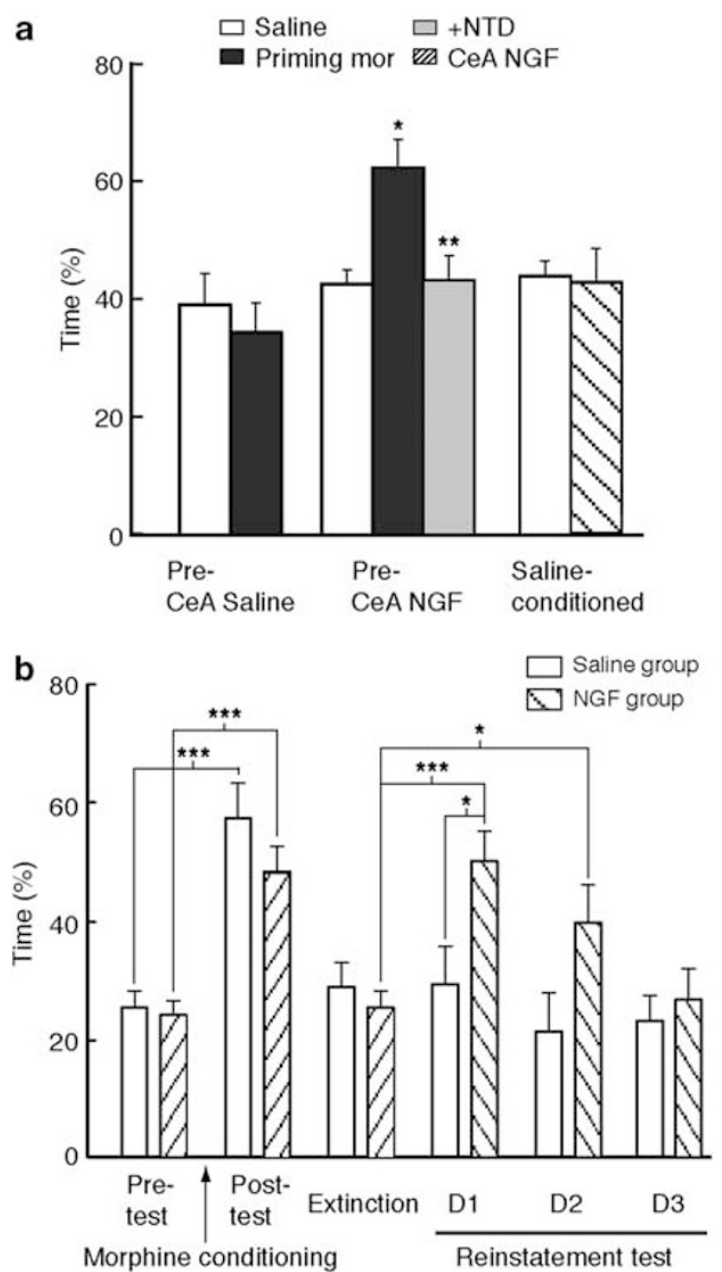

c

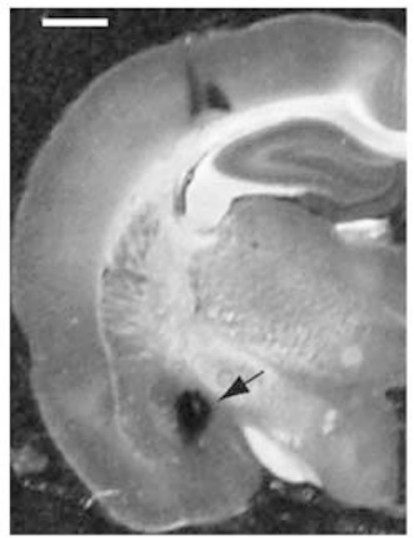

Figure 5 NGF substitutes morphine to induce reward sensitization. (a) Preference behaviors in priming morphine-conditioned naive rats pretreated by CeA infusion of saline $\left(F_{(1,6)}=1.08, n=7\right.$ rats $)$ or NGF $(0.05 \mu \mathrm{g}$, $F_{(1,5)}=14.80, n=6$ rats $)$ or NGF plus NTD $\left(0.45 \mu \mathrm{g}, F_{(1,5)}=34.25, n=6\right.$ rats), and in saline-conditioned rats $(n=4)$ with similar CeA infusion of saline or $\operatorname{NGF}\left(F_{(1,3)}=0.08\right)$. (b) Conditioning with NGF, infused bilaterally into the $\mathrm{CeA}(0.05 \mu \mathrm{g})$, reinstated prior morphine-induced CPP. After the extinction of morphine-induced CPP (saline/morphine, $F_{(5,25)}=9.89$; NGF/ morphine, $F_{(5,35)}=10.86$ ), rats were conditioned with NGF in NGF group $(n=8)$ or saline in saline group $(n=6)$ and then tested on the 3 days (DID3) following the completion of conditioning (two-way ANOVA: conditioning session, $F_{(5,60)}=25.21, p<0.001$; interaction: $F_{(5,60)}=7.63$, $p<0.00 \mathrm{I}$ ). (c) A photomicrograph showing the infusion site in the CeA marked by an injected dye (arrow). Scale bar is $1 \mathrm{~mm}$. Summarized data are mean \pm SEM. $* p<0.05$, *** $p<0.0$ I, **** $p<0.00$ I. Mor, morphine.
BDNF), which is activated by cocaine-induced histone hyperacetylation and is directly associated with addictive behaviors of cocaine (Graham et al, 2007; Schroeder et al, 2008). However, little is known about epigenetic modulations induced by addicting opioids and their target genes. In this study, we provide several lines of evidence showing that $\mathrm{Ngf}$ is an important gene epigenetically regulated by opioids and its upregulation in the CeA may be directly linked to the behavior of opioid reward and sensitization.

Both neurotrophins BDNF and NGF have diverse trophic effects on structural modifications and functional plasticity of central synapses in the adult brain (Chao and Bothwell, 2002; Poo, 2001). Recent addiction studies have revealed BDNF as a key protein that facilitates behaviors of cocaine addiction (Graham et al, 2007; Lu et al, 2004). However, how BDNF promotes these addiction behaviors remains largely unclear. In this regard, a recent study in neurons of prefrontal cortex shows that cocaine withdrawal-induced $\mathrm{BDNF}$ reduces surface expression of $\mathrm{GABA}_{\mathrm{A}}$ receptors, thereby augmenting excitatory synaptic activity and contributing to locomotor hypersensitivity in cocaine withdrawal (Lu et al, 2010). This study in amygdala neurons demonstrates reward-promoting effects of NGF in behavioral responses to initial and subsequent opioids. Thus, it seems that both BDNF and NGF have consistent roles in promoting behaviors of drug addiction through functional coordination within specific brain regions in the brain's reward system.

Previous reports of DOR roles in drug addiction are inconsistent. Systemic administration of a DOR agonist reduces cocaine self-administration in monkeys (Do Carmo et al, 2006), whereas infusion of a DOR agonist into the nucleus accumbens reinstates cocaine-seeking behavior in rodents (Simmons and Self, 2009). Genetic deletion of DOR decreases the conditioned rewarding effect of morphine (Chefer and Shippenberg, 2009), but does not change mouse self-administration of morphine into the ventral tegmental area (David et al, 2008). Using a reward model with opioidinduced new DOR function, this study shows a reward- and sensitivity-promoting effect of CeA DOR through upregulated NGF signaling, which is in line with a previous report that systemic blockade of DOR prevents prior morphine exposure-induced sensitization to morphine reward (Shippenberg et al, 2009). How DOR mediates this behavioral effect through modulation of glutamate transmission is still unknown. Although glutamate synaptic activity is critical in the mechanisms of drug reward and addiction (Bie et al, 2009b; Hyman et al, 2006; Kenny et al, 2009; Zhu et al, 2007), the DOR effect may depend on dynamic release of endogenous opioid peptides, DOR cellular locations, and state-dependent activity of glutamate synapses.

This study provides an NGF-mediated mechanism for the behavior of opioid-induced reward sensitization. However, as both NGF and histone acetylation returned to baseline levels after CPP extinction, it is likely that other long-lasting mechanisms exist that maintain a drug-sensitized state. Nevertheless, the current findings of reward sensitivitypromoting effects of NGF may offer useful information on our understanding of molecular mechanisms underlying opioid sensitization, which is essential for the development of clinical therapies in the treatment of drug addiction and relapse. 


\section{ACKNOWLEDGEMENTS}

This work was supported by the National Institute on Drug Abuse grants DA025826, DA023069, and DA027541.

\section{DISCLOSURE}

The authors declare no conflict of interest.

\section{REFERENCES}

Baxter MG, Murray EA (2002). The amygdala and reward. Nat Rev Neurosci 3: 563-573.

Bie B, Zhang Z, Cai YQ, Zhu W, Zhang Y, Dai J et al (2010). Nerve growth factor-regulated emergence of functional delta-opioid receptors. J Neurosci 30: 5617-5628.

Bie B, Zhu W, Pan ZZ (2009a). Ethanol-induced delta-opioid receptor modulation of glutamate synaptic transmission and conditioned place preference in central amygdala. Neuroscience 160: 348-358.

Bie B, Zhu W, Pan ZZ (2009b). Rewarding morphine-induced synaptic function of delta-opioid receptors on central glutamate synapses. J Pharm Exp Therap 329: 290-296.

Cahill CM, Holdridge SV, Morinville A (2007). Trafficking of deltaopioid receptors and other G-protein-coupled receptors: implications for pain and analgesia. Trends Pharmacol Sci 28: 23-31.

Carlezon Jr WA, Nestler EJ (2002). Elevated levels of GluR1 in the midbrain: a trigger for sensitization to drugs of abuse? Trends Neurosci 25: 610-615.

Chao MV, Bothwell M (2002). Neurotrophins: to cleave or not to cleave. Neuron 33: 9-12.

Chefer VI, Shippenberg TS (2009). Augmentation of morphineinduced sensitization but reduction in morphine tolerance and reward in delta-opioid receptor knockout mice. Neuropsychopharmacology 34: 887-898.

Commons KG (2003). Translocation of presynaptic delta opioid receptors in the ventrolateral periaqueductal gray after swim stress. J Comp Neurol 464: 197-207.

Contet C, Kieffer BL, Befort K (2004). Mu opioid receptor: a gateway to drug addiction. Curr Opin Neurobiol 14: 370-378.

Cornish JL, Lontos JM, Clemens KJ, McGregor IS (2005). Cocaine and heroin ('speedball') self-administration: the involvement of nucleus accumbens dopamine and mu-opiate, but not deltaopiate receptors. Psychopharmacology (Berl) 180: 21-32.

David V, Matifas A, Gavello-Baudy S, Decorte L, Kieffer BL, Cazala P (2008). Brain regional Fos expression elicited by the activation of mu- but not delta-opioid receptors of the ventral tegmental area: evidence for an implication of the ventral thalamus in opiate reward. Neuropsychopharmacology 33: 1746-1759.

Do Carmo GP, Mello NK, Rice KC, Folk JE, Negus SS (2006). Effects of the selective delta opioid agonist SNC80 on cocaineand food-maintained responding in rhesus monkeys. Eur $J$ Pharmacol 547: 92-100.

Dulac C (2010). Brain function and chromatin plasticity. Nature 465: 728-735.

Finnin MS, Donigian JR, Cohen A, Richon VM, Rifkind RA, Marks PA et al (1999). Structures of a histone deacetylase homologue bound to the TSA and SAHA inhibitors. Nature 401: 188-193.

Gottfried JA, O’Doherty J, Dolan RJ (2003). Encoding predictive reward value in human amygdala and orbitofrontal cortex. Science 301: 1104-1107.

Graham DL, Edwards S, Bachtell RK, DiLeone RJ, Rios M, Self DW (2007). Dynamic BDNF activity in nucleus accumbens with cocaine use increases self-administration and relapse. Nat Neurosci 10: 1029-1037.
Hack SP, Bagley EE, Chieng BC, Christie MJ (2005). Induction of delta-opioid receptor function in the midbrain after chronic morphine treatment. J Neurosci 25: 3192-3198.

Heberlein A, Muschler M, Frieling H, Behr M, Eberlein C, Wilhelm $\mathrm{J}$ et al (2011). Epigenetic down regulation of nerve growth factor during alcohol withdrawal. Addic Biol, e-pub ahead of print 11 March 2011, PMID 21392176.

Hyman SE, Malenka RC, Nestler EJ (2006). Neural mechanisms of addiction: the role of reward-related learning and memory. Annu Rev Neurosci 29: 565-598.

Jenuwein T, Allis CD (2001). Translating the histone code. Science 293: $1074-1080$.

Jones S, Bonci A (2005). Synaptic plasticity and drug addiction. Curr Opin Pharmacol 5: 20-25.

Kenny PJ, Chartoff E, Roberto M, Carlezon Jr WA, Markou A (2009). NMDA receptors regulate nicotine-enhanced brain reward function and intravenous nicotine self-administration: role of the ventral tegmental area and central nucleus of the amygdala. Neuropsychopharmacology 34: 266-281.

Koob GF (2008). A role for brain stress systems in addiction. Neuron 59: 11-34.

Koob GF, Kenneth Lloyd G, Mason BJ (2009). Development of pharmacotherapies for drug addiction: a Rosetta stone approach. Nat Rev Drug Discov 8: 500-515.

Kouzarides T (2007). Chromatin modifications and their function. Cell 128: 693-705.

Kurdistani SK, Tavazoie S, Grunstein M (2004). Mapping global histone acetylation patterns to gene expression. Cell 117: 721-733.

Le Merrer J, Becker JA, Befort K, Kieffer BL (2009). Reward processing by the opioid system in the brain. Physiol Rev 89: 1379-1412.

Lu H, Cheng PL, Lim BK, Khoshnevisrad N, Poo MM (2010). Elevated BDNF after cocaine withdrawal facilitates LTP in medial prefrontal cortex by suppressing GABA inhibition. Neuron 67: 821-833.

Lu L, Dempsey J, Liu SY, Bossert JM, Shaham Y (2004). A single infusion of brain-derived neurotrophic factor into the ventral tegmental area induces long-lasting potentiation of cocaine seeking after withdrawal. J Neurosci 24: 1604-1611.

Luscher C, Malenka RC (2011). Drug-evoked synaptic plasticity in addiction: from molecular changes to circuit remodeling. Neuron 69: 650-663.

Ma J, Zhang Y, Kalyuzhny AE, Pan ZZ (2006). Emergence of functional $\{$ delta\}-opioid receptors induced by chronic morphine. Mol Pharmacol 69: 1137-1145.

MacDonald JL, Roskams AJ (2009). Epigenetic regulation of nervous system development by DNA methylation and histone deacetylation. Prog Neurobiol 88: 170-183.

Matthes HW, Maldonado R, Simonin F, Valverde O, Slowe S, Kitchen I et al (1996). Loss of morphine-induced analgesia, reward effect and withdrawal symptoms in mice lacking the mu-opioid-receptor gene. Nature 383: 819-823.

Pan ZZ (1998). mu-Opposing actions of the kappa-opioid receptor. Trends Pharmacol Sci 19: 94-98.

Poo MM (2001). Neurotrophins as synaptic modulators. Nat Rev Neurosci 2: 24-32.

Robison AJ, Nestler EJ (2011). Transcriptional and epigenetic mechanisms of addiction. Nat Rev Neurosci 12: 623-637.

Russo SJ, Dietz DM, Dumitriu D, Morrison JH, Malenka RC, Nestler EJ (2010). The addicted synapse: mechanisms of synaptic and structural plasticity in nucleus accumbens. Trends Neurosci 33: 267-276.

Schmidt BL, Tambeli CH, Barletta J, Luo L, Green P, Levine JD et al (2002). Altered nucleus accumbens circuitry mediates paininduced antinociception in morphine-tolerant rats. J Neurosci 22: 6773-6780. 
Schroeder FA, Penta KL, Matevossian A, Jones SR, Konradi C, Tapper AR et al (2008). Drug-induced activation of dopamine $\mathrm{D}(1)$ receptor signaling and inhibition of class I/II histone deacetylase induce chromatin remodeling in reward circuitry and modulate cocaine-related behaviors. Neuropsychopharmacology 33: 2981-2992.

Shippenberg TS, Chefer VI, Thompson AC (2009). Deltaopioid receptor antagonists prevent sensitization to the conditioned rewarding effects of morphine. Biol Psychiatry 65: 169-174.

Siggins GR, Martin G, Roberto M, Nie Z, Madamba S, De Lecea L (2003). Glutamatergic transmission in opiate and alcohol dependence. Ann NY Acad Sci 1003: 196-211.

Simmons D, Self DW (2009). Role of mu- and delta-opioid receptors in the nucleus accumbens in cocaine-seeking behavior. Neuropsychopharmacology 34: 1946-1957.

Strahl BD, Allis CD (2000). The language of covalent histone modifications. Nature 403: 41-45.
Tzschentke TM (2007). Measuring reward with the conditioned place preference (CPP) paradigm: update of the last decade. Addic Biol 12: 227-462.

Waldhoer M, Bartlett SE, Whistler JL (2004). Opioid receptors. Annu Rev Biochem 73: 953-990.

Wang Y, Krishnan HR, Ghezzi A, Yin JC, Atkinson NS (2007). Druginduced epigenetic changes produce drug tolerance. PLoS Biol 5: e265.

Ward SJ, Roberts DC (2007). Microinjection of the delta-opioid receptor selective antagonist naltrindole $5^{\prime}$-isothiocyanate site specifically affects cocaine self-administration in rats responding under a progressive ratio schedule of reinforcement. Behav Brain Res 182: 140-144.

Zhang Z, Cai Y, Zou F, Bie B, Pan ZZ (2011). Epigenetic suppression of GAD65 expression mediates persistent pain Nat Med 17: 1448-1455.

Zhu W, Bie B, Pan ZZ (2007). Involvement of non-NMDA glutamate receptors in central amygdala in synaptic actions of ethanol and ethanol-induced reward behavior. J Neurosci 27: 289-298.

Supplementary Information accompanies the paper on the Neuropsychopharmacology website (http://www.nature.com/npp) 